Article

\title{
Silver Nanoparticles Using Eucalyptus or Willow Extracts (AgNPs) as Contact Lens Hydrogel Components to Reduce the Risk of Microbial Infection
}

\author{
Andreas K. Rossos ${ }^{1}$, Christina N. Banti ${ }^{1, * \mathbb{D}}$, Panagiotis K. Raptis ${ }^{1}$, Christina Papachristodoulou ${ }^{2}$, \\ Ioannis Sainis ${ }^{3}$, Panagiotis Zoumpoulakis ${ }^{4}\left(\mathbb{D}\right.$, Thomas Mavromoustakos ${ }^{5}$ (D) and Sotiris K. Hadjikakou ${ }^{1,6, *(D)}$
}

check for updates

Citation: Rossos, A.K.; Banti, C.N.; Raptis, P.K.; Papachristodoulou, C.; Sainis, I.; Zoumpoulakis, P.; Mavromoustakos, T.; Hadjikakou, S.K. Silver Nanoparticles Using Eucalyptus or Willow Extracts (AgNPs) as Contact Lens Hydrogel Components to Reduce the Risk of Microbial Infection. Molecules 2021 26, 5022. https://doi.org/10.3390/ molecules26165022

Academic Editor:

Piersandro Pallavicini

Received: 26 July 2021

Accepted: 16 August 2021

Published: 19 August 2021

Publisher's Note: MDPI stays neutral with regard to jurisdictional claims in published maps and institutional affiliations.

Copyright: (c) 2021 by the authors. Licensee MDPI, Basel, Switzerland. This article is an open access article distributed under the terms and conditions of the Creative Commons Attribution (CC BY) license (https:/ / creativecommons.org/licenses/by/ $4.0 /)$.
1 Section of Inorganic and Analytical Chemistry, Department of Chemistry, University of Ioannina, 45110 Ioannina, Greece; arossos@uoi.gr (A.K.R.); panagiwtisraptis93@yahoo.gr (P.K.R.)

2 Department of Physics, University of Ioannina, 45110 Ioannina, Greece; xpapaxri@uoi.gr

3 Cancer Biobank Center, University of Ioannina, 45110 Ioannina, Greece; isainis@uoi.gr

4 Laboratory of Chemistry, Analysis and Design of Food Processes, Department of Food Science and Technology, University of West Attica, 12243 Attica, Greece; pzoump@eie.gr

5 Organic Chemistry Laboratory, Department of Chemistry, University of Athens Greece, 15571 Athens, Greece; tmavrom@chem.uoa.gr

6 University Research Center of Ioannina (URCI), Institute of Materials Science and Computing, 45110 Ioannina, Greece

* Correspondence: cbanti@uoi.gr (C.N.B.); shadjika@uoi.gr (S.K.H.); Tel.: +30-2651-008362 (C.N.B.); +30-2651-008374 (S.K.H.)

Abstract: Eucalyptus leaves (ELE) and willow bark (WBE) extracts were utilized towards the formation of silver nanoparticles (AgNPs(ELE), AgNPs(WBE)). AgNPs(ELE) and AgNPs(WBE) were dispersed in polymer hydrogels to create pHEMA@AgNPs(ELE)_2 and pHEMA@AgNPs(WBE)_2 using hydroxyethyl-methacrylate (HEMA). The materials were characterized in a solid state by X-ray fluorescence (XRF) spectroscopy, X-ray powder diffraction analysis (XRPD), thermogravimetric differential thermal analysis (TG-DTA), differential scanning calorimetry (DTG/DSC) and attenuated total reflection spectroscopy (ATR-FTIR) and ultraviolet visible (UV-vis) spectroscopy in solution. The antimicrobial potential of the materials was investigated against the Gram-negative bacterial strain Pseudomonas aeruginosa (P. aeruginosa) and the Gram-positive bacterial strain of the genus Staphylococcus epidermidis (S. epidermidis) and Staphylococcus aureus (S. aureus), which are involved in microbial keratitis. The percentage of bacterial viability of P. aeruginosa and S. epidermidis upon their incubation over the pHEMA@AgNPs(ELE)_2 discs is interestingly low (28.3 and 6.8\% respectively), while the inhibition zones (IZ) formed are $12.3 \pm 1.7$ and $13.2 \pm 1.2 \mathrm{~mm}$, respectively. No in vitro toxicity of this material towards human corneal epithelial cells (HCEC) was detected. Despite its low performance against S. aureus, pHEMA@AgNPs(ELE)_2 could be an efficient candidate towards the development of contact lenses that reduces microbial infection risk.

Keywords: silver nanoparticles; eucalyptus leaves extract; willow bark extract; antimicrobial materials; hydrogels; contact lens

\section{Introduction}

Contact lenses have been widely used in recent decades [1-4]. However, they are associated with bacterial infections such as microbial keratitis (MK) [1-4]. Bacteria such as P. aeruginosa, S. epidermidis and S. aureus often colonize materials such as contact lenses [2,3]. This means that there is a requirement for novel materials that can retain the benefits of typical contact lenses without the peril of severe bacterial infections $[5,6]$. Contact lenses are typically made from hydrogels based on pHEMA; this gives contact lenses the desirable water and oxygen permeability $[7,8]$. The dispersion of an antimicrobial agent gives antibacterial properties to the polymeric material $[5,6,9]$. 
Plant extracts are used as reducing of capping agents for the chemical synthetic procedure of nanomaterials [10]. The type of plant extract used is known to influence the characteristics of the nanoparticles produced, since different plant extracts contain different concentrations of organic reducing agents [10]. Eucalyptus leaves contain a wide range of active components such as $p$-cymene (42.1\%), eucalyptol (1,8-cineole) $(14.1 \%), \alpha$-pinene $(12.7 \%)$ and $\alpha$-terpineol $(10.7 \%)$ (Scheme 1) [11,12]. The extract from the leaves or essential oil from the leaves of Eucalyptus spp. has been reported to possess antifungal, antibacterial and antioxidant properties [13].<smiles>Cc1ccc(C(C)C)cc1</smiles>

$p$-Cymene

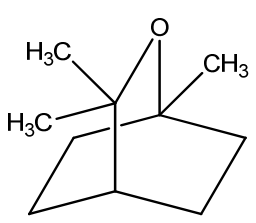

Eucalyptol<smiles>CC1=CCC2CC1C2(C)C</smiles>

a-Pinene<smiles>CC1=CCC(C(C)(C)O)CC1</smiles>

a-terpinoel

Scheme 1. Molecular formulae of the main components of Eucalyptus [11,12].

Willow species extract, deriving either from bark or leaves, has already been used against bacteria (A. alternaria, A. niger, $M$. hiemalis, P. notatum and S. commune) with remarkable effect [14]. Analysis of aqueous extracts of willow bark has shown the presence of at least 11 related salicylate compounds including salicin, saligenin, salicylic acid, isosalicin, salidroside, picein, triandrin, salicoylsalicin, salicortin, isosalipurpuroside and salipurpuroside (Scheme 2) [15].<smiles>O=C(O)c1ccccc1O</smiles>

Salicylic acid<smiles>OCc1ccccc1O</smiles>

Saligenin<smiles>OCc1ccccc1OC1OC(CO)C(O)C(O)C1O</smiles><smiles>CCC1OC(OCc2ccccc2Cl)C(O)C(O)C1O</smiles><smiles>CC(=O)c1ccc(OC2OC(CO)C(O)C(O)C2O)cc1</smiles><smiles>OCC1OC(O/C=C\c2ccc(O)cc2)C(O)C(O)C1O</smiles><smiles>CCOC(=O)c1ccccc1O</smiles>

triandrin<smiles>O=C(/C=C/c1ccc(O)cc1)c1c(O)cc(O)cc1OC1OC(CO)C(O)C(O)C1O</smiles><smiles>O=C1CC(c2ccc(O)cc2)Oc2cc(O)cc(OC3OC(CO)C(O)C(O)C3O)c21</smiles>

Scheme 2. Molecular formulae of the main components of willow bark extract [15]. 
Silver compounds are known antimicrobial agents $[9,16]$. Recently, the metal-organic framework (MOF) of formula $\left\{\left[\mathrm{Ag}_{6}\left(\mu_{3}-\mathrm{HMNA}\right)_{4}\left(\mu_{3}-\mathrm{MNA}\right)_{2}\right]^{2-} \cdot\left[\left(\mathrm{Et}_{3} \mathrm{NH}\right)^{+}\right]_{2} \cdot 2(\mathrm{DMSO}) \cdot\left(\mathrm{H}_{2} \mathrm{O}\right)\right\}$ (AGMNA) $\left(\mathrm{H}_{2} \mathrm{MNA}=2\right.$ mercapto-nicotinic acid) has been successfully incorporated in polymer hydrogel pHEMA, providing antimicrobial contact lenses [5]. Silver nanoparticles, on the other hand, constitute an alternative way to overcome antimicrobial resistance [17]. Recently, the synthesis of silver nanoparticles, using eucalyptus leaf extract, and their antimicrobial activity against two Gram-negative bacteria (P. aeruginosa and E. coli) and two Gram-positive bacteria (S. aureus and B. subtilis) have been reported [12,18].

Two strategies have been developed, with the aim of forming new antimicrobial materials for contact lenses that are able to reduce microbial infection risk. One involves the usage of silver nanoparticles using extracts from natural products as a combined reducing and capping agent [6] while the second is the use of small molecules, which also act as antimicrobial agents $[5,6,9,19]$. The materials pHEMA@ORLE_2 and pHEMA@AgNPs(ORLE)_2, which contain silver nanoparticles AgNPs(ORLE) from oregano leaves' extract (ORLE), were reported on recently [6]. The antimicrobial ability of these materials against the bacteria that are involved in the microbial contamination of contact lenses demonstrates the value of further research into this strategy [6]. In continuing our work in this research area [6], silver nanoparticles (AgNPs(ELE), $\mathrm{AgNPs}(\mathrm{WBE})$ ) using eucalyptus leaves (ELE) and willow bark (WBE) extracts were synthesized, and were incorporated in pHEMA hydrogels, forming the materials pHEMA@AgNPs(ELE)_2 and pHEMA@AgNPs(WBE)_2. The materials were characterized by XRF, XRPD, TG-DTA, DTG/DSC, ATR-FTIR and UV-vis spectroscopy. The antimicrobial potential of the materials was evaluated against the Gram-negative bacterial strain P. aeruginosa and the Gram-positive ones, S. epidermidis and $S$. aureus, which are involved in the microbial contamination of contact lenses, leading to MK.

\section{Results}

\subsection{General Aspects}

pHEMA cross-linked with ethylene glycol dimethacrylate (EGDMA) is the basis of many types of soft contact lenses made for daily use [5]. In order to evaluate the antimicrobial efficiency of the contact lens (pHEMA@AgNPs(ELE)_2 and pHEMA@AgNPs(WBE)_2), the $\mathrm{AgNPs}(\mathrm{ELE})$ or $\mathrm{AgNPs}(\mathrm{WBE})$ nanoparticles were dispersed in pHEMA in a concentration of $2 \mathrm{mg} / \mathrm{mL}$ during the polymerization procedure [6]. Discs of the materials, $10 \mathrm{~mm}$ in diameter, were cut, cleaned from monomers and stored either in sterilized $\mathrm{NaCl} 0.9 \%$ $w / w$ solution or they dried at $50{ }^{\circ} \mathrm{C}$.

\subsection{X-ray Fluorescence Spectroscopy}

Dry pHEMA@AgNPs(ELE)_2 and pHEMA@AgNPs(WBE)_2 discs were ground to powder. The XRF spectrum of AgNPs(ELE), AgNPs(WBE), pHEMA@AgNPs(ELE)_2 and pHEMA@AgNPs(WBE)_2 powders confirmed the presence of Ag in the materials (Figure 1). The content of silver in AgNPs(ELE), AgNPs(WBE), pHEMA@AgNPs(ELE)_2 and pHEM$\mathrm{A} @ \mathrm{AgNPs}(\mathrm{WBE}) \_2$ was determined at $46 \pm 7,32 \pm 5,0.30 \pm 0.04$ and $0.20 \pm 0.03 \% w / w$, respectively. The latter suggests the successful encapsulation of AgNPs within pHEMA.

\subsection{X-ray Powder Diffraction Analysis (XRPD)}

The crystallite size of $\mathrm{AgNPs}(\mathrm{ELE})$ and $\mathrm{AgNPs}(\mathrm{WBE})$ was determined with XRPD (Figure 2). The Voigt shape function was used during the peak fitting. The XRPD pattern clearly showed the main peaks at (20) 38.2, 44.4, 64.5 and $77.6^{\circ}$ (AgNPs(ELE)) corresponding to the (111), (200), (220) and (311) planes, as well as at (20) 38.4, 64.8 and $77.7^{\circ}$ corresponding to the (111), (200), (220) and (311) planes (AgNPs(WBE)), respectively. The silver nanoparticles were face-centered, cubic and crystalline in nature [20] (correlated to JCPDS card: number 04-0783) [21]. 


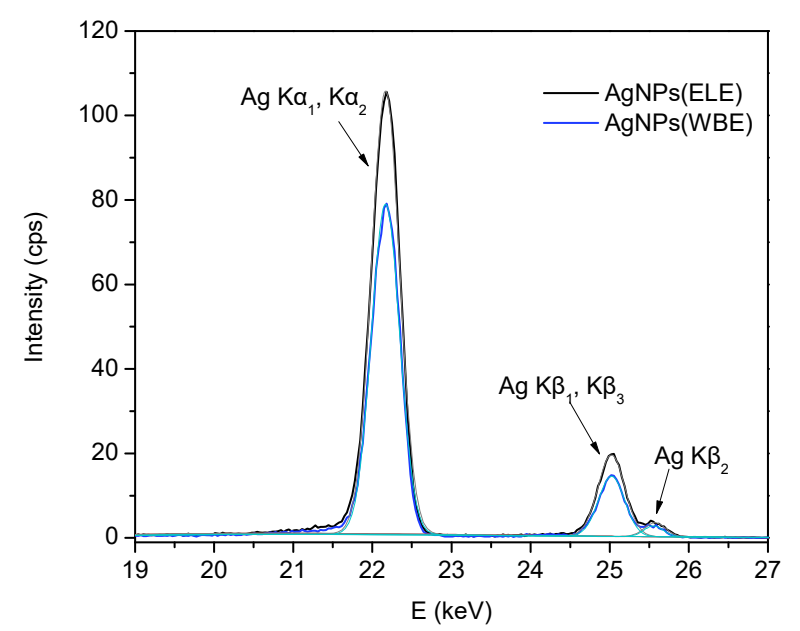

(A)

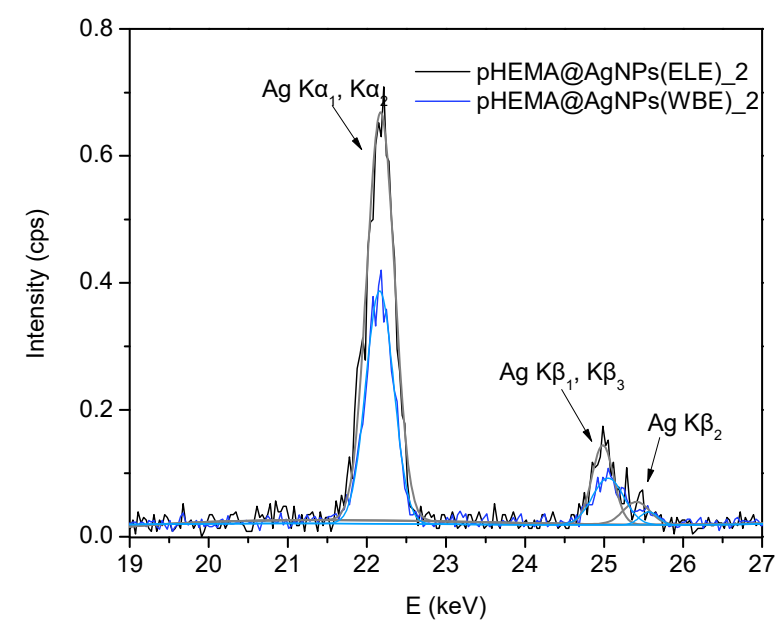

(B)

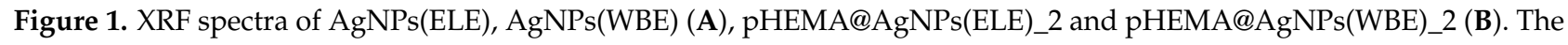
$\mathrm{Ag} \mathrm{K}_{\mathrm{a}}$ was used to determine Ag content within the samples.

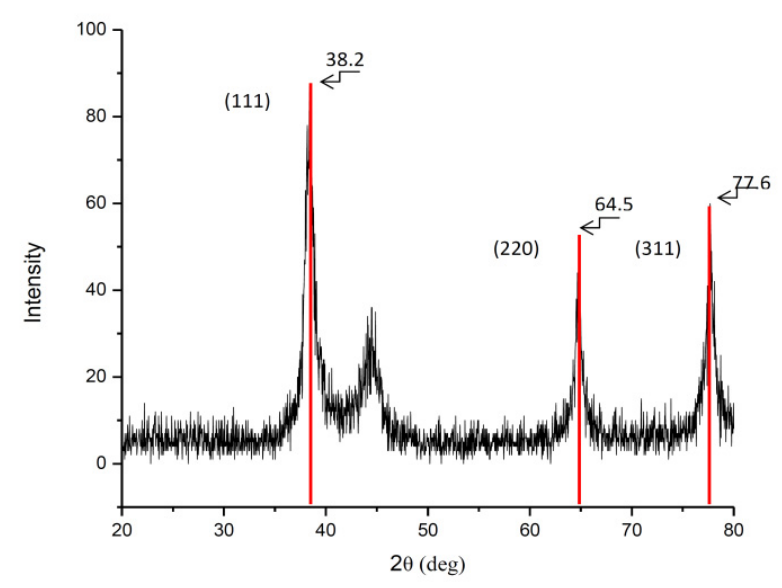

(A)

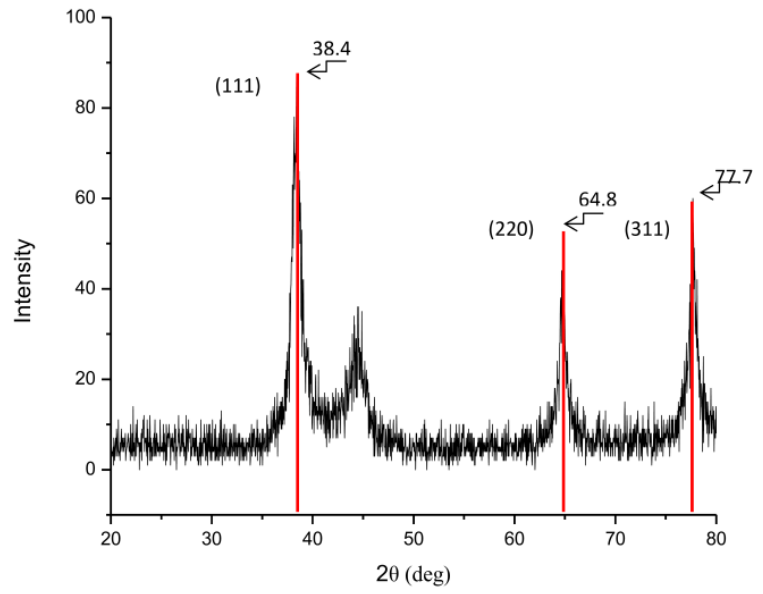

(B)

Figure 2. Powder X-ray diagram of $\operatorname{AgNPs}(\mathrm{ELE})(\mathrm{A})$ and $\operatorname{AgNPs}(\mathrm{WBE})(\mathbf{B})$ with the characteristic Bragg peaks of Ag nanoparticles.

Peak width was defined as the full width at half maximum (FWHM), knowing that the peak width varies inversely with crystallite size. The average crystalline size of the silver nanoparticles was estimated using the Debye-Scherrer's Equation (1) [22]

$$
\mathrm{B}(2 \theta)=0.9 \times \lambda /(\mathrm{L} \times \cos (\theta))
$$

where $B$ = peak width, which is inversely proportional to crystallite size $(\mathrm{L})$.

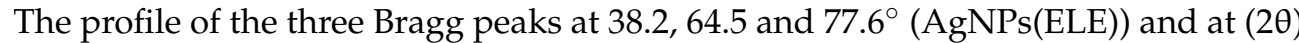
38.4, 64.8 and $77.7^{\circ}(\mathrm{AgNPs}(\mathrm{WBE}))$ were calculated, and the following corresponding crystallite sizes were obtained: AgNPs(ELE), 21.3, 15.0 and $11.1 \mathrm{~nm}$ (or 213, 150, $111 \AA$ ) and for $\operatorname{AgNPs}(\mathrm{WBE})$ ), 7.9, 11.5 and $7.8 \mathrm{~nm}$ (or 79, 115, $78 \AA$ A ). Therefore, the average crystallite size values are $15.8 \mathrm{~nm}(\mathrm{AgNPs}(\mathrm{ELE}))$ and $9.1 \mathrm{~nm}(\mathrm{AgNPs}(\mathrm{WBE}))$.

2.4. Thermo Gravimetric Analysis of $A g N P s(E L E), A g N P s(W B E), p H E M A$, pHEMA@AgNPs(ELE)_2 and pHEMA@AgNPs(WBE)_2

2.4.1. Differential Scanning Calorimetry (DSC)

In order to ascertain whether AgNPs(ELE) and AgNPs(WBE) nanoparticles interact with pHEMA in a solid state, towards a mixture or a composite material, DSC studies on the powder of dry pHEMA and pHEMA@AgNPs(ELE)_2 or pHEMA@AgNPs(WBE)_2 
were performed (Figure 3). The endothermic transitions in the DSC diagram of the free pHEMA at $444{ }^{\circ} \mathrm{C}$ is observed at $432{ }^{\circ} \mathrm{C}$ pHEMA@AgNPs(ELE) 2 and at $429{ }^{\circ} \mathrm{C}$ in pHEMA@AgNPs(WBE)_2, respectively, implying an interaction between the material's components with pHEMA and therefore the formation of composite materials.

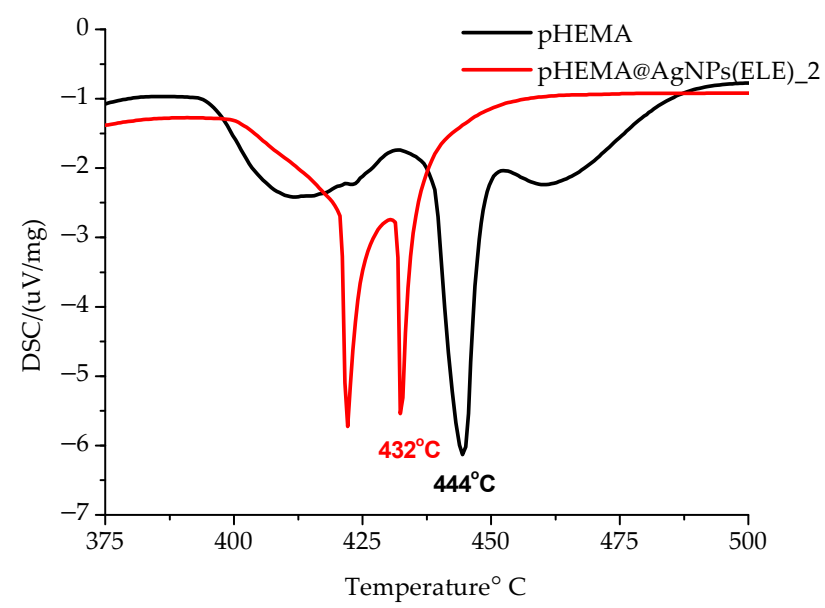

(A)

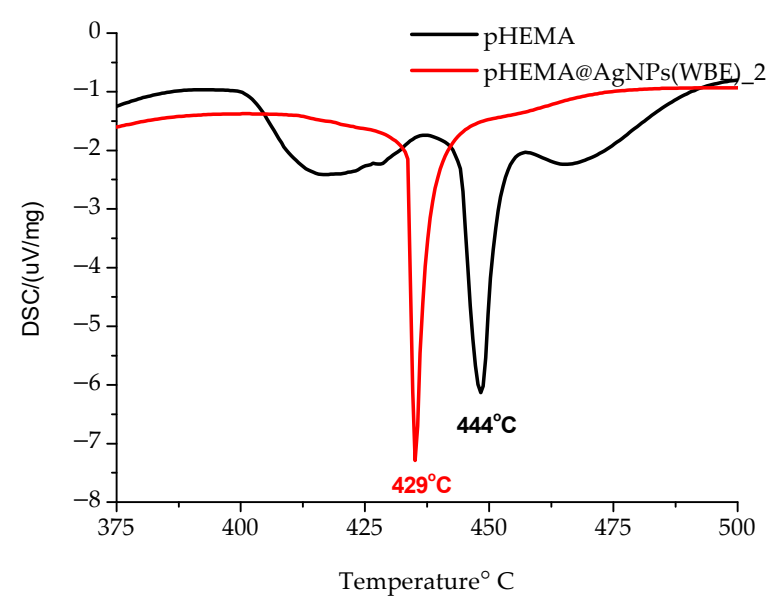

(B)

Figure 3. Differential scanning calorimetry (DSC) thermo-diagrams of pHEMA, pHEMA@AgNPs(ELE)_2 (A) and pHEMA@AgNPs(WBE)_2 (B).

\subsubsection{Thermal Decomposition}

TG/DTA analysis was performed under air on the powder of dry AgNPs(ELE), $\operatorname{AgNPs}(\mathrm{WBE})$, pHEMA@AgNPs(ELE)_2 and pHEMA@AgNPs(WBE)_2 with an increasing temperature rate of $10{ }^{\circ} \mathrm{C} \mathrm{min}-1$ from ambient up to $500{ }^{\circ} \mathrm{C}$ (Figure S1). The silver nanoparticles AgNPs(ELE) decomposes with three endothermic steps at 55-90, 90-370 and $427-450{ }^{\circ} \mathrm{C}$, while the and $\mathrm{AgNPs}(\mathrm{WBE})$ with six ones at 50-85, 85-248, 248-404, 404-452, 452-478 and $478-510{ }^{\circ} \mathrm{C}$ and (AgNPs(WBE)) (Figure S1). The composite materials pHEMA@AgNPs(ELE)_2 and pHEMA@AgNPs(WBE)_2 decompose with three endothermic steps at 55-160, 243-380 and 427-450 ${ }^{\circ} \mathrm{C}$ (pHEMA@AgNPs(ELE)_2) and at 55-135, 230-395 and 429-484 ${ }^{\circ} \mathrm{C}$ (pHEMA@AgNPs(WBE)_2) (Figure S1).

\subsection{Attenuated Total Reflection Spectroscopy (ATR-FTIR)}

ATR-FTIR spectra of AgNPs(ELE) and AgNPs(WBE) exhibited the characteristic stretching vibration of bands of the alcohols and phenolic groups of plant extracts, which also appeared on the spectra of free extracts (Figure 4). The C-H stretching vibration band at $2918 \mathrm{~cm}^{-1}$ (ELE or WBE), the C-OH band at 1024 or $1036 \mathrm{~cm}^{-1}$ (ELE or WBE) and the aromatic $C=C$ vibration band at 1610 or $1603 \mathrm{~cm}^{-1}$ (ELE or WBE) of alcohols or phenols of the ingredients (Schemes 1 and 2) [12], are observed at 2908, 1015 and $1562 \mathrm{~cm}^{-1}$ (Ag$\mathrm{NPs}(\mathrm{ELE}))$, respectively, as well as at 2916, 1022 and $1610 \mathrm{~cm}^{-1}(\mathrm{AgNPs}(\mathrm{WBE}))$, indicating the presence of the ELE or WBE in the AgNPs(ELE) or AgNPs(WBE). Thus, the ELE and WBE act as both reducing and a capping agents.

\subsection{Ultraviolet Visible Spectroscopy (UV-vis)}

UV-vis spectroscopy was implemented for the silver nanoparticles' size determination. The UV-vis spectra in dd water solution $1 \mathrm{mg} / \mathrm{mL}$ of $\mathrm{AgNPs}(\mathrm{ELE})$ and $\mathrm{AgNPs}(\mathrm{WBE})$ showed absorbance at $\lambda \max , 428$ and $447 \mathrm{~nm}$, respectively (Figure 5 ). This band has been assigned to the collective resonance of electrons at the surface known as surface plasmon resonance (SPR) of the silver nanoparticles [23,24]. Since the size is directly related to the $\lambda$ max of SPRs, particle with diameters of 40 (AgNPs(ELE)) and 60 (AgNPs(WBE)) nm were concluded [6]. These values are larger than the corresponding ones of the crystallite found from XRPD patterns, due to solvation effect. 


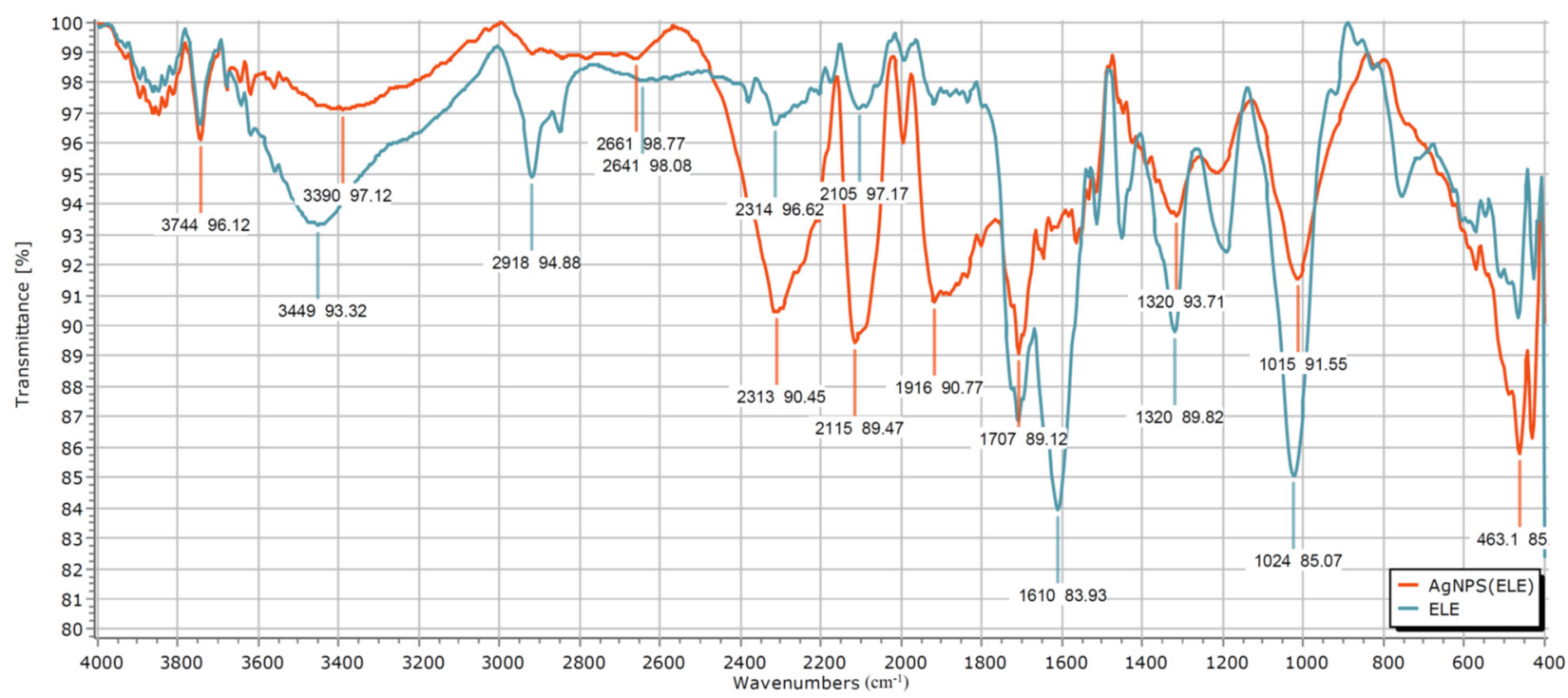

(A)

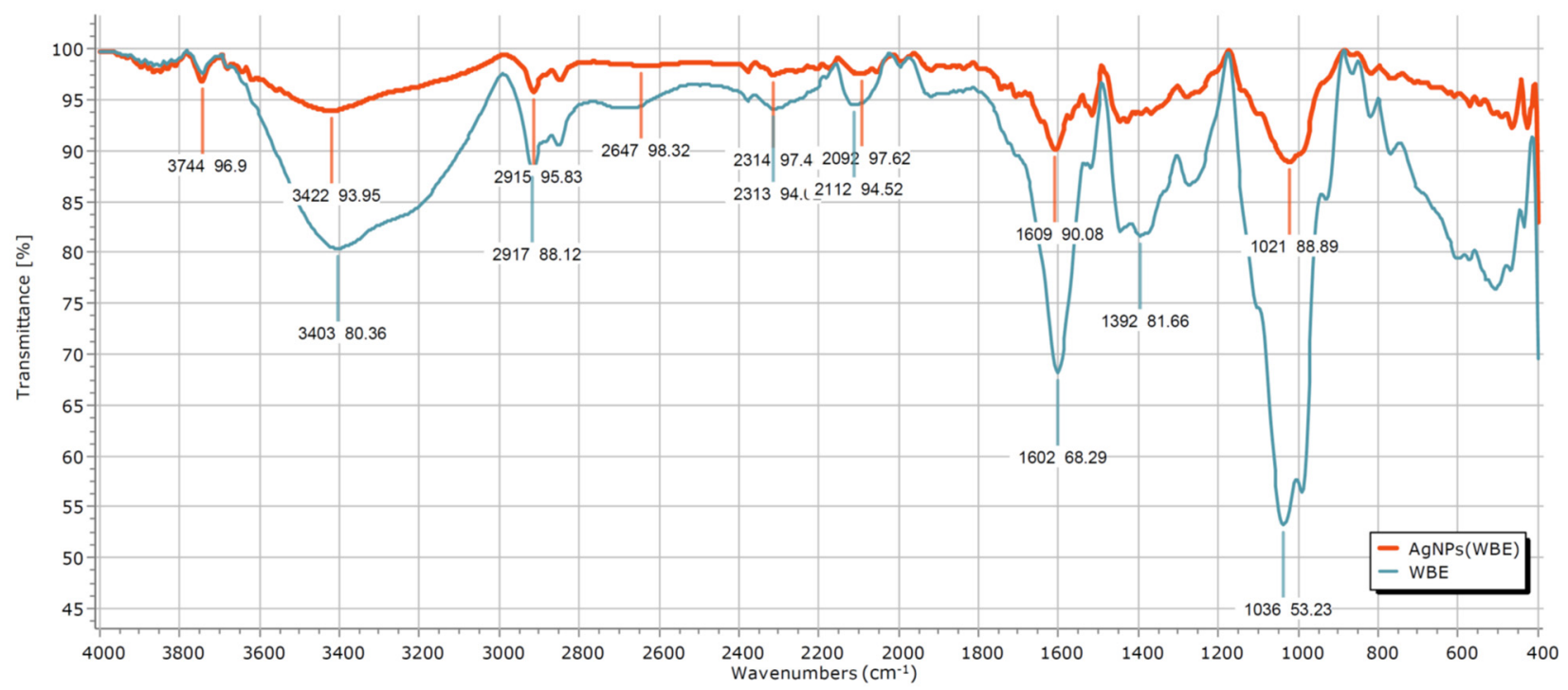

(B)

Figure 4. ATR-FTIR specra of ELE, $\operatorname{AgNPs}(\mathrm{ELE})(\mathbf{A})$ and WBE, $\operatorname{AgNPs}(\mathrm{WBE})(\mathbf{B})$.

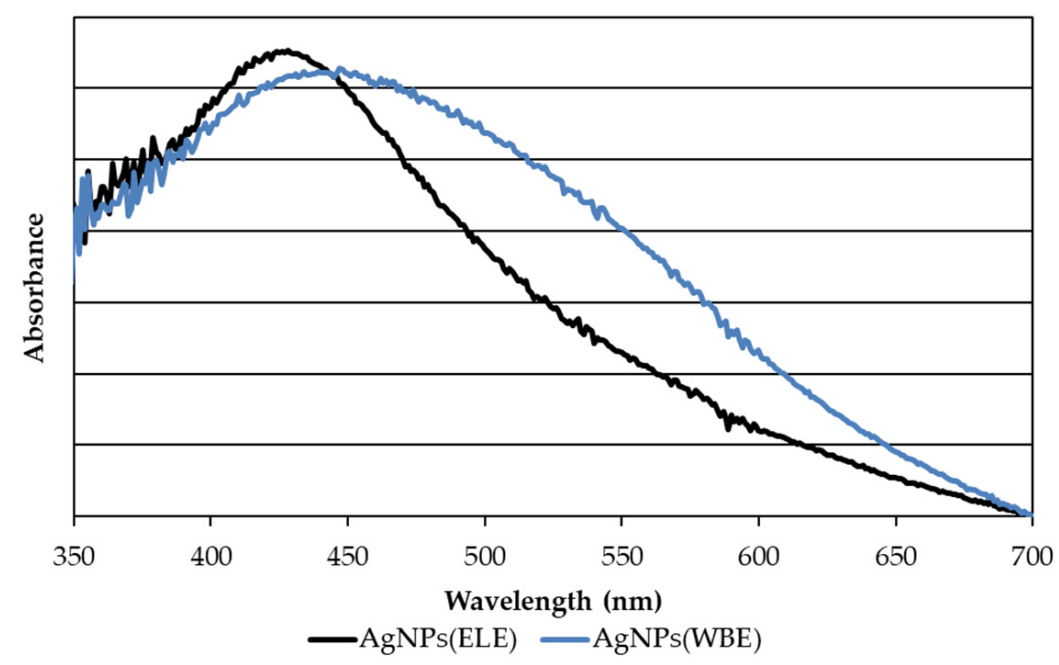

Figure 5. UV-vis spectra of $\mathrm{AgNPs}(\mathrm{ELE})$ and $\mathrm{AgNPs}(\mathrm{WBE})$ in double-distilled (dd) water. 


\subsection{Antimicrobial Study}

2.7.1. Determination of the Inhibition Zone (IZ) through Agar Disc-Diffusion Method

The sensitivity of the bacteria P. aeruginosa, S. epidermidis and S. aureus against the agents (ELE, WBE, AgNPs(ELE) and $\mathrm{AgNPs}(\mathrm{WBE})$ ) was evaluated with an agar diffusion assay. Paper discs $10 \mathrm{~mm}$ in diameter were soaked in dd water solution of the agent $(2 \mathrm{mg} / \mathrm{mL})$. The discs were placed on agar plates and they were incubated at $37^{\circ} \mathrm{C}$ for $20 \mathrm{~h}$. The inhibition zone (IZ) was classed as the area without bacterial lawn around the disc $[5,6,9,25]$ (Table 1$)$. The size of the IZ around the filter paper disc indicated the sensitivity of the bacterial strain in the tested formulation [25]. Among the agents, $\mathrm{AgNPs}(\mathrm{ELE})$ gave the greatest IZ against microbial strains (Table 1). The IZs of AgNPs(ELE) against $P$. aeruginosa, S. epidermidis and S. aureus were 15.2, 17.0 and $15.2 \mathrm{~mm}$, respectively, whereas, ELE and WBE showed no IZ (Table 1). The microbe strains were classified in three categories according to the size of the IZ caused by an antimicrobial agent: (i) strains, where the agent causes an IZ $\geq 17 \mathrm{~mm}$, were classed as susceptible; (ii) those where the agent created an IZ between 13 to $16 \mathrm{~mm}(13 \leq \mathrm{IZ} \leq 16 \mathrm{~mm})$ were intermediate; while in (iii) those where the agent caused an IZ $\leq 12 \mathrm{~mm}$ the microbes were considered as resistant strains [26]. Therefore, the strains studied here (P. aeruginosa, S. epidermidis and S. aureus) responded intermediately to $\mathrm{AgNPs}(\mathrm{ELE})$, while they were considered as resistant strains towards the rest of the agents tested in this work (ELE, WBE and AgNPs(WBE)) [26].

Table 1. Inhibition zones (IZs) of ELE, WBE, AgNPs(ELE) and AgNPs(WBE) at $2 \mathrm{mg} / \mathrm{mL}$ pHEMA@ELE_2,pHEMA@WBE_2,pHEMA@AgNPs(ELE)_2 and pHEMA@AgNPs(WBE)_2) against P. aeruginosa, S. epidermidis and S. aureus.

\begin{tabular}{cccc}
\hline & P. aeruginosa & S. epidermidis & S. aureus \\
\hline & \multicolumn{3}{c}{ Inhibition Zones $\mathbf{( m m )}$} \\
\hline AgNPs(ELE) & $15.2 \pm 1.2$ & $17.0 \pm 1.1$ & $15.2 \pm 1.6$ \\
ELE & $\mathrm{ND}$ & $\mathrm{ND}$ & $\mathrm{ND}$ \\
AgNPs(WBE) & $11.9 \pm 0.9$ & $11.3 \pm 0.6$ & $11.0 \pm 0.0$ \\
WBE & $\mathrm{ND}$ & $\mathrm{ND}$ & $\mathrm{ND}$ \\
pHEMA@AgNPs(ELE)_2 & $12.3 \pm 1.7$ & $13.2 \pm 1.2$ & $13.2 \pm 1.4$ \\
pHEMA@ELE_2 & $\mathrm{ND}$ & $\mathrm{ND}$ & $\mathrm{ND}$ \\
pHEMA@AgNPs(WBE)_2 & $11.2 \pm 0.3$ & $11.0 \pm 1.0$ & $11.5 \pm 0.6$ \\
pHEMA@WBE_2 & $\mathrm{ND}$ & $\mathrm{ND}$ & $\mathrm{ND}$ \\
\hline & \multicolumn{4}{c}{} \\
\hline pHEMA@AgNPs(ELE)_2 & 28.3 & Bacteria Viability (\%) & 85.3 \\
pHEMA@ELE_2 & 94.6 & 6.8 & 98.7 \\
pHEMA@AgNPs(WBE)_2) & 73.6 & 93.5 & 92.5 \\
pHEMA@WBE_2 & 90.5 & 81.6 & 97.3 \\
\hline
\end{tabular}

$\mathrm{ND}=$ no inhibitory zone (IZ) was developed.

Moreover, both ELE and WBE, alone and in combination with pHEMA, were not active at all in the disinfection process, even though their AgNPs and composite materials exhibit antimicrobial activity (Table 1). This was because plant extracts act both as reducing and capping agents in the synthesis of nanoparticles, leading to species of different sizes. The size, surface coatings or capping agents and surface charge have been identified as important factors for AgNPs efficacy. The smaller the nanoparticles, the higher their activity. Thus, when the size is $<10 \mathrm{~nm}$, the activity is at a maximum. Moreover, AgNPs in the range between 10 and $15 \mathrm{~nm}$, where they have higher stability, biocompatibility and antimicrobial activity, exhibit compromised activity. AgNPs over $50 \mathrm{~nm}$, were not active, probably because their large dimension reduces the interaction with the bacterial surface and also impedes their internalization [27]. The variation in the sizes of AgNPs(ELE) and $\mathrm{AgNPs}(\mathrm{WBE})$ in solution (40 and $60 \mathrm{~nm}$, respectively) rationalize the difference in antimicrobial activity between $\mathrm{AgNPs}(\mathrm{ELE})$ and $\mathrm{AgNPs}(\mathrm{WBE})$. 
In order to check the sensitivity of bacteria to pHEMA, pHEMA@ELE_2, pHEMA@WBE_2, pHEMA@AgNPs(ELE)_2 and pHEMA@AgNPs(WBE)_2, discs with a diameter of $10 \mathrm{~mm}$ were placed in Petri agar plates and inhibition zones were determined after $20 \mathrm{~h}$ (Figure 6). The inhibition zones developed by pHEMA@AgNPs(ELE)_2 against $P$. aeruginosa, S. epidermidis and S. aureus (Table 1, Figure 6) were 12.3 $\pm 1.7,13.2 \pm 1.2$ and $13.2 \pm 1.4 \mathrm{~mm}$, respectively; while no or negligible inhibition zones were developed when pHEMA, pHEMA@ELE_2, pHEMA@WBE_2 or pHEMA@AgNPs(WBE)_2 were used.

For the evaluation of microbial viability, P. aeruginosa, S. epidermidis and S. aureus $\left(5 \times 10^{5} \mathrm{cfu} / \mathrm{mL}\right)$ were cultured in test tubes with broth culture medium, while pHEMA@ELE_2, pHEMA@WBE_2, pHEMA@AgNPs(ELE)_2 and pHEMA@AgNPs(WBE)_2 discs were settled in the bottom (Figure S2). Then, the tubes were stirred continuously for $20 \mathrm{~h}$. The microbes' density in the broth solutions were then determined by measuring their optical density at $620 \mathrm{~nm}$ and comparing that with the corresponding control solution (the corresponding one, which contains the same number of microbes, in the same volume of broth solution and was subject to no treatment with a disc). The percentage of bacterial density of $P$. aeruginosa and S. epidermidis upon their incubation with pHEMA@AgNPs(ELE)_2 discs was 28.3 and 6.8\%, respectively (Table 1). Negligible activity in bacterial density was observed upon their treatment by discs of pure pHEMA or pHEMA@ELE_2, pHEMA@WBE_2 or pHEMA@AgNPs(WBE)_2 (Table 1). However, the optical density (OD) of the broth culture medium at $620 \mathrm{~nm}$ shows the microbial density; therefore, their viability still remains to be examined. In order to confirm whether the remaining microbes in broth solution were viable or not, $4 \mu \mathrm{L}$ of the supernatant solutions of $P$. aeruginosa and S. epidermidis bacteria, which were, initially, treated with pHEMA@AgNPs(ELE)_2 discs, were inoculated in an agar plate. The occurrence of microbial colonies suggests the viability of the microbes after treatment and therefore a percentage reduction in the density also corresponds to the microbial viability (Figure 7). Moreover, the biomaterials reduce microbial proliferation as long as they are present in the medium, without, however, their total elimination (Figure 7).

The hydrogel of pHEMA@AgNPs(ELE)_2, which contains the AgNPs from eucalyptus leaves, exhibits superior activity against the P. aeruginosa and S. epidermidis in relation to those made by the rest of materials. pHEMA@AgNPs(ELE)_2 reduces the P. aeruginosa, S. epidermidis and S. aureus microbes' proliferation.

\subsubsection{In Vitro Toxicity against Normal Human Corneal Epithelial Cells (HCEC)}

The hydrogels pHEMA@AgNPs(ELE)_2 and pHEMA@AgNPs(WBE)_2 were tested for in vitro toxicity against HCEC cells upon their incubation for a period of $24 \mathrm{~h}$. The incubation of HCEC cells in the presence of pHEMA@AgNPs(ELE)_2 and pHEMA@AgNPs(WBE)_2 discs decreased their viability by $64.4 \pm 5.7$ and $72.8 \pm 8.5 \%$, respectively, compared with the cells that were incubated with pure pHEMA. According to ISO 10993-5, if the percent of cell viability is higher than $\geq 70 \%$, then the material should be considered as non-cytotoxic [28,29]; therefore, the materials tested in this work are considered as low or nontoxic. 


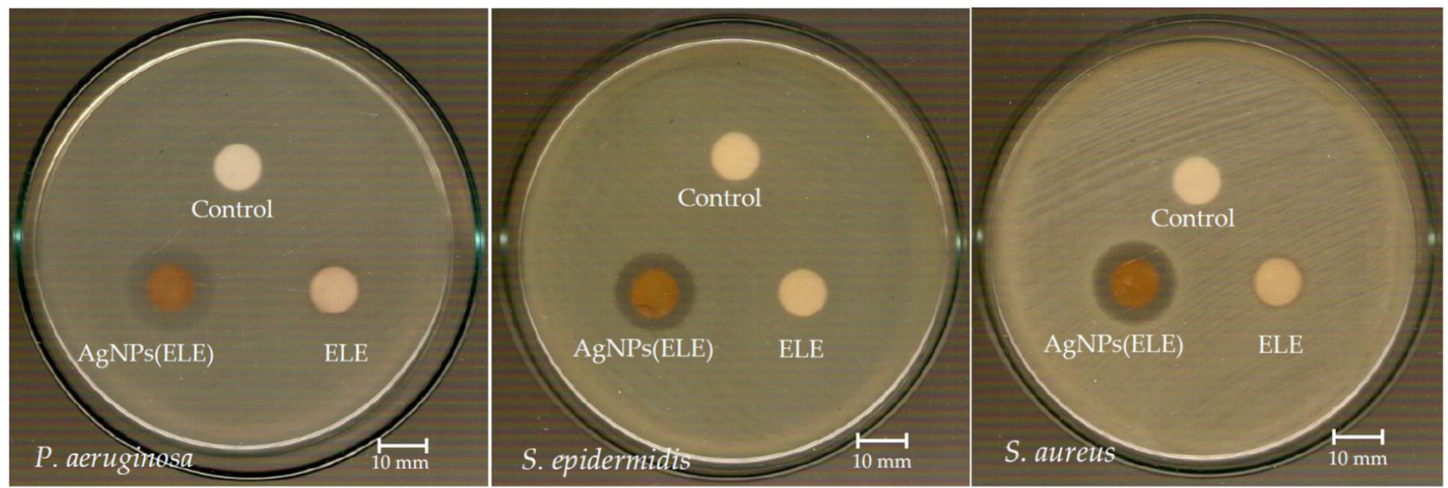

(A)

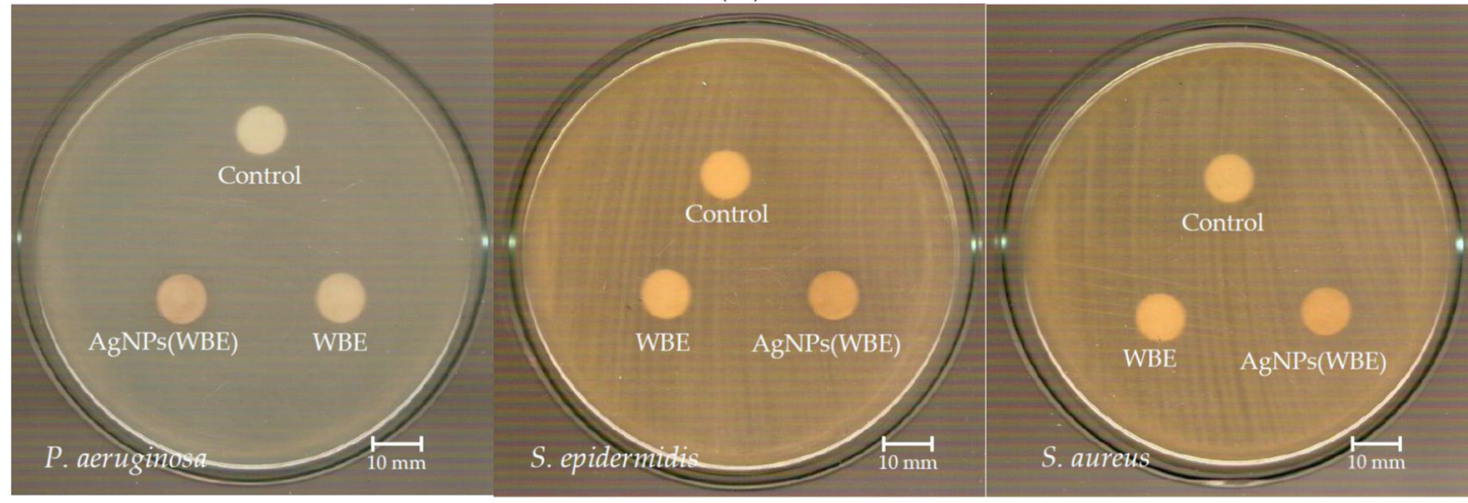

(B)

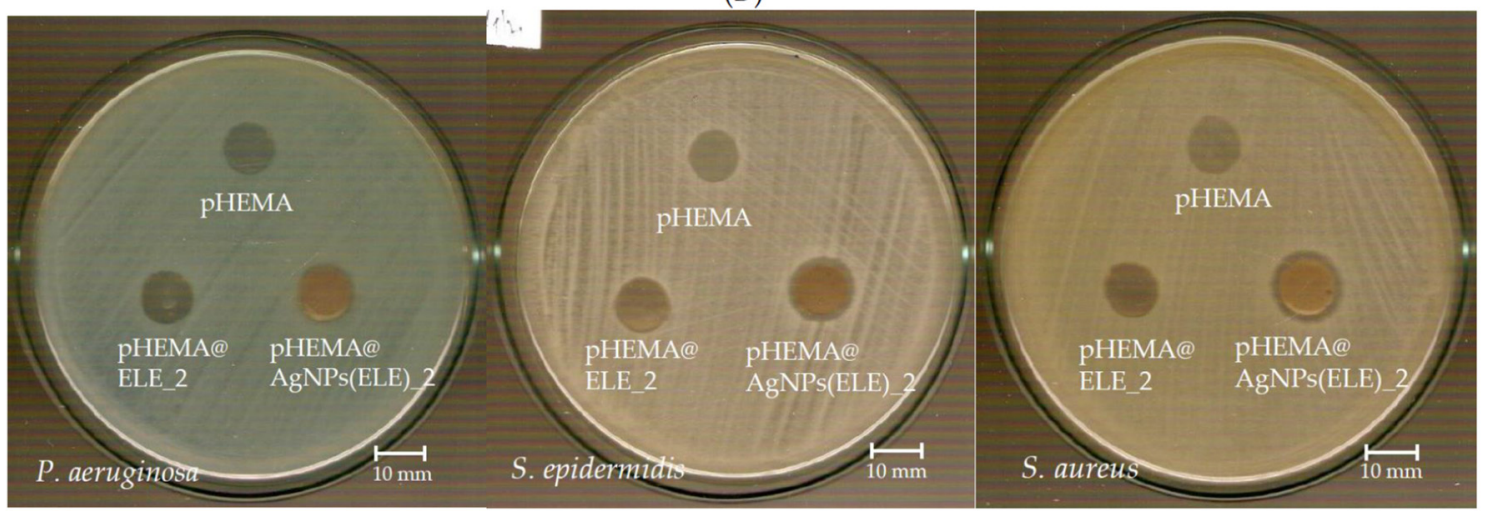

(C)

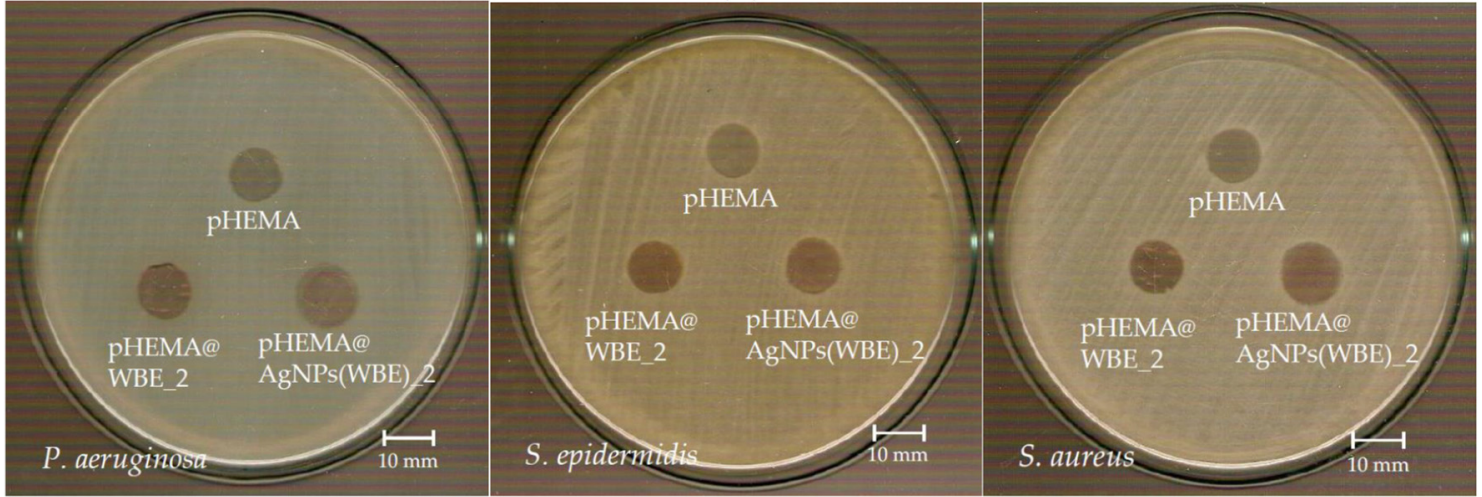

(D)

Figure 6. Inhibition zones of ELE and $\operatorname{AgNPs}(\operatorname{ELE})(\mathbf{A}), \operatorname{AgNPs}(\mathrm{WBE})$ and WBE at $2 \mathrm{mg} / \mathrm{mL}$ (B), pHEMA, pHEMA@ELE_2, pHEMA@AgNPs(ELE)_2 (C) and pHEMA, pHEMA@WBE_2 and pHEMA@AgNPs(WBE)_2 (D) against P. aeruginosa, S. epidermidis, S. aureus. 


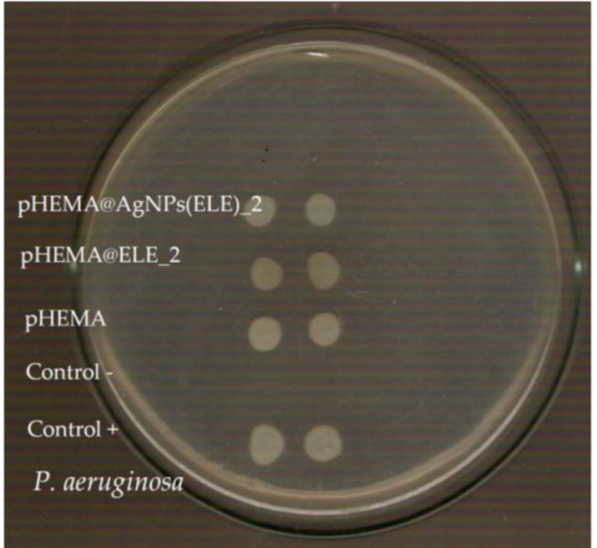

(A)

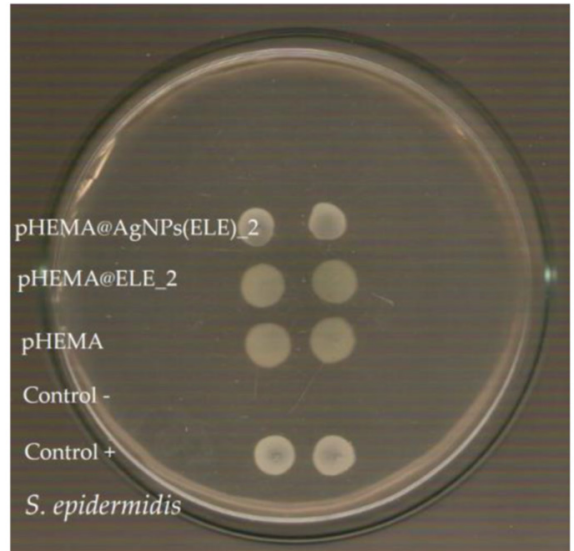

(B)

Figure 7. Bacterial colonies which were grown when $4 \mu \mathrm{L}$ of the supernatant solutions of $P$. aeruginosa (A) and S. epidermidis (B) bacteria, which were, initially, treated with pHEMA@AgNPs(ELE)_2 discs, were inoculated in an agar plate.

\section{Experimental Methods}

\subsection{Materials and Instruments}

Dimethylsulfoxide (DMSO, Riedel-de Haen, Seelze, Germany) was used without any further purification. Silver nitrate $\left(\mathrm{AgNO}_{3}\right.$, ) was purchased from Degussa (Berlin, Germany). For lens preparation, 2-hydroxyethyl-methacrylate (pHEMA), ethylene-glycoledimethacrylate (EGDMA, MERCK, Germany), diphenyl-(2,4,6-trimethylbenzoyl)-phosphine oxide (TPO 97\%, Sigma-Aldrich, Steinheim, Germany) as well as sodium chloride ( $\mathrm{NaCl}$, MERCK) and hydrochloric acid ( $\mathrm{HCl} 37 \%$, MERCK) were used. Tryptone tryptophan medium, beef extract powder, peptone bacteriological and soy peptone were purchased from Biolife. Agar (Louis, MO, USA, product of Spain) and yeast extracts were purchased from Fluka Analytical (Switzerland). D(+)-glucose and di-potassium hydrogen phosphate trihydrate were purchased from Merck. Melting points were measured in open tubes with a Stuart Scientific apparatus and were uncorrected. A UV-1600 PC series spectrophotometer of VWR was used to obtain electronic absorption spectra. ATR-FT-IR spectra in the region of 4000-370 $\mathrm{cm}^{-1}$ were obtained with a Cary 670 FTIR spectrometer (Agilent Technologies Inc., Santa Clara, CA, USA). XRF measurement was carried out with Rigaku NEX QC EDXRF analyzer, (Austin, TX, USA).

\subsection{Preparation of ELE, WBE and $A g N P_{s}(E L E), A g N P s(W B E)$}

Dry eucalyptus leaves and willow bark (4 g) were refluxed using a Soxhlet apparatus with $50 \mathrm{~mL}$ dd water for $3 \mathrm{~h}$. The extracts ELE and WBE were filtrated off and clear filtrates were obtained. In a $250 \mathrm{~mL}$ beaker, $10 \mathrm{~mL}$ ELE and WBE and $170 \mathrm{mg} \mathrm{AgNO} 3(1 \mathrm{mmol})$ were added. The beaker was placed in a $700 \mathrm{~W}$ microwave oven for $2 \mathrm{~min}$. Consequently, the solution was placed in the sonicator (ultrasonic) for $10 \mathrm{~min}$. The solution is centrifugal at $6000 \mathrm{rpm}$ for $20 \mathrm{~min}$ and the $\mathrm{AgNPs}(\mathrm{ELE})$ and $\mathrm{AgNPs}(\mathrm{WBE})$ were collected.

Synthesis of pHEMA@ELE_2, pHEMA@AgNPs(ELE)_2, pHEMA@WBE_2 and pHEMA@AgNPs(WBE)_2: Hydrogels of ELE, WBE and AgNPs(ELE), AgNPs(WBE) were obtained as follows: $2.7 \mathrm{~mL}$ of 2-hydroxyethyl-methacrylate (HEMA) was mixed with $2 \mathrm{~mL}$ of double distilled water (ddw), which contained ELE, WBE, AgNPs(ELE) or AgNPs(WBE) $(2 \mathrm{mg} / \mathrm{mL}$ ) and $10 \mu \mathrm{L}$ of EGDMA. The solution was then degassed by bubbling with nitrogen for $15 \mathrm{~min}$. TPO initiator $(6 \mathrm{mg}$ ) was added to the solution and mixed for $5 \mathrm{~min}$ at $800 \mathrm{rpm}$. The solution was poured into the mold and was then placed under a 15 watt UV mercury lamp $(\lambda \max =280 \mathrm{~nm})$ for photopolymerization for $40 \mathrm{~min}$. Unreacted monomers were removed, by immersing the gel in water for $15 \mathrm{~min}$. Discs of $10 \mathrm{~mm}$ diameter were cut, and they were washed by immersion in water, $\mathrm{NaCl} 0.9 \%, \mathrm{HCl} 0.1 \mathrm{M}$ then again in water. The discs were then dried at $40{ }^{\circ} \mathrm{C}$ until no weight change would occur. To emphasize the 
composite materials, the indicator " 2 " highlighted the use of $2 \mathrm{mg} / \mathrm{mL}$ of ingredients during the polymerization process of pHEMA

$X$-ray Fluorescence Spectroscopy: The experiments were carried out using a Rigaku NEX QC EDXRF analyzer The XRF measurements were duplicated previously reported [6] using an Am-241 radioisotopic source (exciting radiation $59.5 \mathrm{keV}$ ). A Si (Li) detector was used for the detection of X-ray fluorescence. In each measurement, 2000 counts were collected on the weaker K $\alpha$ peak. The experiments were duplicated using a Rigaku NEX QC EDXRF analyzer.

X-ray Powder Diffraction (XRPD): This study was performed as previously reported [6]. The X-ray powder diffraction study was accomplished by a diffraction-meter D8 AdvanceBruker, from the Department of Physics at the University of Ioannina. Radiation CuKa $(40 \mathrm{kV}, 40 \mathrm{~mA}, \lambda \mathrm{K} \alpha)$ and the monochromator system of diffracted beam were used. The $\mathrm{X}$-ray powder diffraction data were collected in the area of $2 \theta$ angles between $2^{\circ}$ and $80^{\circ}$ using a rotation step $0.02^{\circ}$ and time of $2 \mathrm{~s}$ per step. All samples measured with the above diffraction-meter were in fine-grained powder form.

Thermogravimetric Differential Thermal Analysis (TG-DTA), Differential Scanning Calorimetry (DTG/DSC): This study was conducted as previously reported [6]. The DTA/TG measurements were performed in DTG/TG NETZSCH STA 449C. The samples were placed in a platinum capsule while an-alumina was used as a reference. The rate of temperature increasing was $10^{\circ} \mathrm{C} /$ minute from ambient conditions up to $500^{\circ} \mathrm{C}$ under air.

\subsection{Biological Tests}

Bacterial Strains: The following bacterial strains were used in the experiment: P. aeruginosa (PAO1), S. epidermidis (ATCC ${ }^{\circledR} 14990^{\mathrm{TM}}$ ) and S. aureus (ATCC ${ }^{\circledR} 25923^{\mathrm{TM}}$ ) [6]. The bacterial strain P. aeruginosa PAO1 was kindly donated by the Laboratory of Biochemistry at the University of Ioannina, Greece [6]. The biological experiments were performed in triplicate. The statistical analysis software package included in MS Office excel (Version 2107) was used for the data processing.

Effects on the growth of microbial strains: This experiment was conducted as previously reported $[5,6,9,19]$. In brief, bacterial strains were plated onto trypticase soy agar and were incubated for $18-24 \mathrm{~h}$, at $37^{\circ} \mathrm{C}$. Three to five isolated colonies with the same morphological appearance were selected from a fresh agar plate using a sterile loop and transferred into a tube containing $2 \mathrm{~mL}$ of sterile saline solution. The optical density at $620 \mathrm{~nm}$ was adjusted to 0.1 which corresponded to $10^{8} \mathrm{cfu} / \mathrm{mL}[5,6,9,19]$.

For the determination of the inhibition zone (IZ): The procedure was performed as previously reported $[5,6,9,19]$. A standardized inoculum $\left(10^{8} \mathrm{cfu} / \mathrm{mL}\right)$ of the microorganisms was incubated in agar plates. A cotton swab was dipped in the inoculum $\left(10^{8} \mathrm{cfu} / \mathrm{mL}\right)$ of the microorganisms. The excess fluid was removed by turning the swab against the inside of the tube. The inoculum was spread evenly over the entire surface of the agar Petri dishes in three directions. Discs of pHEMA pHEMA@ELE_2, pHEMA@AgNPs(ELE)_2, pHEMA@WBE_2 and pHEMA@AgNPs(WBE)_2 with a $10 \mathrm{~mm}$ diameter, or ELE, WBE and $\mathrm{AgNPs}(\mathrm{ELE}), \mathrm{AgNPs}(\mathrm{WBE})$ at the concentration of $2 \mathrm{mg} / \mathrm{mL}$, were placed on the agar surface and the petri plates were incubated for $20 \mathrm{~h}$. In order to evaluate the viability of microbes on pHEMA pHEMA@ELE_2, pHEMA@AgNPs(ELE)_2, pHEMA@WBE_2 and pHEMA@AgNPs(WBE)_2, discs of the materials were placed in the tests tubes that contained $5 \times 10^{5} \mathrm{cfu} / \mathrm{mL}$ of $P$. aeruginosa, E. coli, S. epidermidis and S. aureus microbes $[5,6,9,19]$. The optical densities of the supernatant solutions were then measured to give the percentage viability of microbes after incubation for $18-24 \mathrm{~h}[5,6,9,19]$. The reference in optical measurement for percentage viability of microbes was the negative control (control( -$)$ ), i.e., the bacterial culture medium without microbes. The positive control (control(+)) was the corresponding one that contained the same number of microbes, in the same volume of broth solution, and was subject to no treatment with a disc. The percentage reduction in microbe density was calculated by the following Equation (2) [30]: 
Bacterial density reduction $(\%)=\frac{\text { Optical density }(\mathrm{OD}) \text { of the broth solution at } 620 \mathrm{~nm}}{\text { Optical density }(\mathrm{OD}) \text { of the control }(+) \text { broth solution at } 620 \mathrm{~nm}} \times 100$

\subsection{Sulforhodamine B Assay}

The HCEC cells were seeded in a 24-well plate at a density of $7.5 \times 10^{4}$ cells/well. After $24 \mathrm{~h}$ of cell incubation, pHEMA pHEMA@AgNPs(ELE)_2 and pHEMA@AgNPs(WBE)_2 were added in each well. After $24 \mathrm{~h}$ of incubation of HCEC cells with the discs, the discs were removed. The culture medium was aspirated and the cells were fixed with $300 \mu \mathrm{L}$ of $10 \%$ cold trichloroacetic acid (TCA). The plate was left for $30 \mathrm{~min}$ at $4{ }^{\circ} \mathrm{C}$, then washed five times with deionized water and left to dry at room temperature for $24 \mathrm{~h}$. Subsequently, in each well, $300 \mu \mathrm{L}$ of $0.4 \%(w / v)$ sulforhodamine B (Sigma) in $1 \%$ acetic acid solution was added, and then they were left at room temperature for $20 \mathrm{~min}$. The dye SRB was removed, and the plate was washed five times with $1 \%$ acetic acid before air drying. Bound SRB was solubilized with $1 \mathrm{~mL}$ of $10 \mathrm{mM}$ un-buffered Tris-base solution. Absorbance was read at $540 \mathrm{~nm}[5,6,9,19]$.

\section{Conclusions}

Antimicrobial composite materials pHEMA@AgNPs(ELE)_2 or pHEMA@AgNPs(WBE)_2 for contact lenses, which are able to reduce microbial infection risks, were prepared by dispersing silver nanoparticles from eucalyptus leaves extracts into pHEMA (which is used in soft contact lenses) during the polymerization process. The most potent antimicrobial hydrogel pHEMA@AgNPs(ELE)_2 eliminates P. aeruginosa, S. epidermidis and S. aureus bacteria by 71.2, 93.2 and $14.7 \%$, respectively. The oregano leaves' extract (ORLE) was also used in the formation of silver nanoparticles AgNPs(ORLE). This was dispersed in pHEMA towards the composite material pHEMA@AgNPs(ORLE)_2. Upon the treatment of P. aeruginosa, S. epidermidis and S. aureus with pHEMA@AgNPs(ORLE)_2 discs, the percentages of bacterial elimination are 33.5, 22.3 and $40.4 \%$, respectively; however, when pHEMA@AgNPs(WBE) 2 is used, the corresponding bacteria eliminations are $26.4,18.4$ and $17.5 \%$, respectively [6]. Therefore, the newly developed pHEMA@AgNPs(ELE)_2 exhibits superior efficiency against $P$. aeruginosa and S. epidermidis than pHEMA@AgNPs(ORLE)_2 or pHEMA@AgNPs(WBE)_2. Moreover, the cell viability of human corneal epithelial HCEC cells upon their incubation with pHEMA@AgNPs(ELE)_2 discs was $64.4 \%$, whereas the corresponding one of pHEMA@AgNPs(ORLE)_2 was 54.9\%, suggesting a lower toxic effect of pHEMA@AgNPs(ELE)_2. In conclusion, pHEMA@AgNPs(ELE)_2 eliminates the P. aeruginosa and S. epidermidis, which colonize contact lenses and cause microbial keratitis, Furthermore, it exhibits low toxic effect on HCEC cells' viability. Thus, pHEMA@AgNPs(ELE)_2 might be an efficient candidate for the development of new contact lenses that are able to inhibit colonization by P. aeruginosa and S. epidermidis and, in turn, reduce the risk of microbial infection.

Supplementary Materials: The following are available online, Figure S1: TGA diagrams of Ag$\mathrm{NPs}(\mathrm{ELE})(\mathbf{A}), \operatorname{AgNPs}(\mathrm{WBE})(\mathbf{B}), \mathrm{pHEMA} @ A g N P s(E L E) \_2$ (C) and pHEMA@AgNPs(WBE)_2 (D); Figure S2: Bacteria viability of pHEMA, pHEMA@ELE_2, pHEMA@AgNPs(ELE)_2, pHEMA@WBE_2 and pHEMA@AgNPs(WBE)_2 against P. aeruginosa (A), S. epidermidis (B), S. aureus (C).

Author Contributions: Conceptualization, S.K.H.; Investigation, A.K.R., P.K.R., C.N.B., I.S., C.P., P.Z. and T.M.; Methodology, C.N.B. and S.K.H.; Supervision, S.K.H.; Validation, S.K.H.; Writing-Original Draft, C.N.B. and S.K.H.; Writing-Review and Editing, C.N.B. and S.K.H. All authors have read and agreed to the published version of the manuscript.

Funding: This research was co-financial supported by the European Union and Greek national funds through the Operational Program Competitiveness, Entrepreneurship and Innovation, under the call RESEARCH-CREATE-INNOVATE (project code: T1EDK-02990).

Institutional Review Board Statement: Not applicable. 
Informed Consent Statement: Not applicable.

Data Availability Statement: The data presented in this study are available in Supplementary Material.

Acknowledgments: (a) The International Graduate Program in "Biological Inorganic Chemistry", which operates at the University of Ioannina within the collaboration of the Departments of Chemistry of the Universities of Ioannina, Athens, Thessaloniki, Patras, Crete and the Department of Chemistry of the University of Cyprus (http:/ / bic.chem.uoi.gr/BIC-En/index-en.html, accessed on 18 August 2021) (b) This research has been co-financed by the European Union and Greek national funds through the Operational Program Competitiveness, Entrepreneurship and Innovation, under the call RESEARCH-CREATE-INNOVATE (project code:T1EDK-02990).

Conflicts of Interest: The authors declare no conflict of interest.

Sample Availability: Samples of the compounds AgNPs(ELE), AgNPs(WBE), pHEMA@AgNPs(ELE)_2 and pHEMA@AgNPs(WBE)_2 are available from the authors.

\section{References}

1. Zimmerman, A.B.; Nixon, A.D.; Rueff, E.M. Contact lens associated microbial keratitis: Practical considerations for the optometrist. Clin. Optom. 2016, 8, 1-12. [CrossRef]

2. Schaefer, F.; Bruttin, O.; Zografos, L.; Guex-Crosier, Y. Bacterial keratitis: A prospective clinical and microbiological study. Br. J. Ophthalmol. 2001, 85, 842-847. [CrossRef] [PubMed]

3. Stapleton, F.; Carnt, N. Contact lens-related microbial keratitis: How have epidemiology and genetics helped us with pathogenesis and prophylaxis. Eye 2012, 26, 185-193. [CrossRef]

4. Xiao, A.; Dhand, C.; Leung, C.M.; Beuerman, R.W.; Ramakrishna, S.; Lakshminarayanan, R. Strategies to design antimicrobial contact lenses and contact lens cases. J. Mater. Chem. B 2018, 6, 2171-2186. [CrossRef]

5. Rossos, A.K.; Banti, C.N.; Kalampounias, A.; Papachristodoulou, C.; Kordatos, K.; Zoumpoulakis, P.; Mavromoustakos, T.; Kourkoumelis, N.; Hadjikakou, S.K. pHEMA@AGMNA-1: A novel material for the development of antibacterial contact lens. Mater. Sci. Eng. C 2020, 111, 110770. [CrossRef] [PubMed]

6. Meretoudi, A.; Banti, C.N.; Raptis, P.K.; Papachristodoulou, C.; Kourkoumelis, N.; Ikiades, A.A.; Zoumpoulakis, P.; Mavromoustakos, T.; Hadjikakou, S.K. Silver nanoparticles from Oregano leaves' extracts as antimicrobial components for non-infected hydrogel contact lenses. Int. J. Mol. Sci. 2021, 22, 3539. [CrossRef] [PubMed]

7. Musgrave, C.S.A.; Fang, F. Contact lens materials: A materials science perspective. Materials 2019, 12, 261. [CrossRef] [PubMed]

8. Wichterle, O.; Lim, D. Hydrophilic gels for biological use. Nature 1960, 185, 117-118. [CrossRef]

9. Milionis, I.; Banti, C.B.; Sainis, I.; Raptopoulou, C.P.; Psycharis, V.; Kourkoumelis, N.; Hadjikakou, S.K. Silver ciprofloxacin (CIPAG): A successful combination of chemically modified antibiotic in inorganic-organic hybrid. J. Biol. Inorg. Chem. 2018, 23, 705-723. [CrossRef]

10. Rahimi-Nasrabadi, M.; Pourmortazavi, S.M.; Shandiz, S.A.; Ahmadi, F.; Batooli, H. Green synthesis of silver nanoparticles using Eucalyptus leucoxylon leaves extract and evaluating the antioxidant activities of extract. Nat. Prod. Res. 2014, 28, 1964-1969. [CrossRef] [PubMed]

11. Dogan, G.; Kara, N.; Bagci, E.; Gur, S. Chemical composition and biological activities of leaf and fruit essential oils from Eucalyptus camaldulensis. Z. Nat. C 2017, 72, 483-489. [CrossRef]

12. Mo, Y.-Y.; Tang, Y.-K.; Wang, S.-Y.; Lin, J.-M.; Zhang, H.-B.; Luo, D.-Y. Green synthesis of silver nanoparticles using eucalyptus leaf extract. Mater. Lett. 2015, 144, 165-167. [CrossRef]

13. Salari, M.H.; Amine, G.; Shirazi, M.H.; Hafezi, R.; Mohammadypour, M. Antibacterial effects of Eucalyptus globulus leaf extract on pathogenic bacteria isolated from specimens of patients with respiratory tract disorders. Clin. Microbiol. Infect. 2006, 12, 194-196. [CrossRef]

14. Masika, P.J.; Afolayan, A.J. Antimicrobial activity of some plants used for the treatment of livestock disease in the Eastern Cape, South Africa. J. Ethnopharmacol. 2002, 83, 129-134. [CrossRef]

15. Shara, M.; Stohs, S.J. Efficacy and safety of white willow bark (Salix alba) extracts. Phytother. Res. 2015, 29, 1112-1116. [CrossRef] [PubMed]

16. Eckhardt, S.; Brunetto, P.S.; Gagnon, J.; Priebe, M.; Giese, B.; Fromm, K.M. Nanobio Silver: Its interactions with peptides and bacteria, and its uses in medicine. Chem. Rev. 2013, 113, 4708. [CrossRef]

17. Wintachai, P.; Paosen, S.; Yupanqui, C.T.; Voravuthikunchai, S.P. Silver nanoparticles synthesized with Eucalyptus critriodora ethanol leaf extract stimulate antibacterial activity against clinically multidrug-resistant Acinetobacter baumannii isolated from pneumonia patients. Microb. Pathog. 2019, 126, 245-257. [CrossRef] [PubMed]

18. Mohammed, A.E. Green synthesis, antimicrobial and cytotoxic effects of silver nanoparticles mediated by Eucalyptus camaldulensis leaf extract. Asian Pac. J. Trop. Biomed. 2015, 5, 382-386. [CrossRef]

19. Karetsi, V.A.; Banti, C.N.; Kourkoumelis, N.; Papachristodoulou, C.; Stalikas, C.D.; Raptopoulou, C.P.; Psycharis, V.; Zoumpoulakis, P.; Mavromoustakos, T.; Sainis, I.; et al. An efficient disinfectant, composite material $\left\{\mathrm{SLS}_{\mathrm{Z}}\left[\mathrm{Zn}_{3}(\mathrm{CitH})_{2}\right]\right\}$ as ingredient for development of sterilized and non infectious contact lens. Antibiotics 2019, 8, 213. [CrossRef] [PubMed] 
20. Shameli, K.; Ahmad, M.B.; Zamanian, A.; Sangpour, P.; Shabanzadeh, P.; Abdollahi, Y.; Zargar, M. Green biosynthesis of silver nanoparticles using Curcuma longa tuber powder. Int. J. Nanomed. 2012, 7, 5603-5610. [CrossRef] [PubMed]

21. Roy, K.; Sarkar, C.K.; Ghosh, C.K. Plant-mediated synthesis of silver nanoparticles using parsley (Petroselinum crispum) leaf extract: Spectral analysis of the particles and antibacterial study. Appl. Nanosci. 2015, 5, 945-951. [CrossRef]

22. Ajitha, B.; Ashok Kumar Reddy, Y.; Sreedhara Reddy, P. Biogenic nano-scale silver particles by Tephrosia purpurea leaf extract and their inborn antimicrobial activity. Spectrochim. Acta Part A 2014, 121, 164-172. [CrossRef] [PubMed]

23. Abdel-Halim, E.S.; Alanazi, H.H.; Al-Deyab, S.S. Utilization of hydroxypropyl carboxymethyl cellulose in synthesis of silver nanoparticles. Int. J. Biol. Macromol. 2015, 75, 467-473. [CrossRef] [PubMed]

24. Garza-Navarro, M.A.; Aguirre-Rosales, J.A.; Llanas-Vázquez, E.E.; Moreno-Cortez, I.E.; Torres-Castro, A.; González-González, V. Totally ecofriendly synthesis of silver nanoparticles from aqueous dissolutions of polysaccharides. Int. J. Polym. Sci. 2013, 436021. [CrossRef]

25. Matuschek, E.; Brown, D.F.J.; Kahlmeter, G. Development of the EUCAST disk difusion antimicrobial susceptibility testing method and its implementation in routine microbiology laboratories. Clin. Microbiol. Infect. 2014, 20, o255-o266. [CrossRef] [PubMed]

26. Wayne, P.A.; Clinical and Laboratory Standards Institute (CLSI). Performance Standards for Antimicrobial Susceptibility Testing; Approved Standard, 25th Informational Supplement, CLSI Document M100-S25; Clinical and Laboratory Standards Institute: Wayne, PA, USA, 2015.

27. Medici, S.; Peana, M.; Nurchi, V.M.; Antonietta Zoroddu, M. Medical uses of silver: History, myths, and scientific evidence. J. Med. Chem. 2019, 62, 5923-5943. [CrossRef]

28. Koski, C.; Sarkar, N.; Bose, S. Cytotoxic and osteogenic effects of crocin and bicarbonate from calcium phosphates for potential chemopreventative and anti-inflammatory applications In Vitro and In Vivo. J. Mater. Chem. B 2020, 8, 2048-2062. [CrossRef] [PubMed]

29. Available online: https://www.iso.org/standard/36406.html (accessed on 19 August 2021).

30. Papadimitriou, A.; Ketikidis, I.; Stathopoulou, M.K.; Banti, C.N.; Papachristodoulou, C.; Zoumpoulakis, L.; Agathopoulos, S.; Vagenas, G.V.; Hadjikakou, S.K. Innovative material containing the natural product curcumin, with enhanced antimicrobial properties for active packaging. Mater. Sci. Eng. C 2018, 84, 118. [CrossRef] 